\title{
Clinical Outcomes and Prognostic Factors for Salivary Duct Carcinoma: A Multi-Institutional Analysis of 141 Patients
}

\begin{abstract}
Kuninori Otsuka, $\mathrm{MD}^{1,2}$, Yorihisa Imanishi, $\mathrm{MD}^{1}$, Yuichiro Tada, $\mathrm{MD}^{3}$, Daisuke Kawakita, $\mathrm{MD}^{4}$, Satoshi Kano, $\mathrm{MD}^{5}$, Kiyoaki Tsukahara, $\mathrm{MD}^{6}$, Akira Shimizu, $\mathrm{MD}^{6}$, Hiroyuki Ozawa, $\mathrm{MD}^{1}$, Kenji Okami, $\mathrm{MD}^{7}$, Akihiro Sakai, $\mathrm{MD}^{7}$, Yuichiro Sato, $\mathrm{MD}^{8}$, Yushi Ueki, $\mathrm{MD}^{8}$, Yukiko Sato, $\mathrm{DDS}^{9}$, Toyoyuki Hanazawa, $\mathrm{MD}^{10}$, Hideaki Chazono, $\mathrm{MD}^{10}$, Kaoru Ogawa, $\mathrm{MD}^{1}$, and Toshitaka Nagao, $\mathrm{MD}^{11}$

${ }^{1}$ Department of Otorhinolaryngology-Head and Neck Surgery, Keio University School of Medicine, Tokyo, Japan; ${ }^{2}$ Department of Otorhinolaryngology, Saiseikai Yokohama Tobu Hospital, Yokohama, Japan; ${ }^{3}$ Department of Head and Neck Oncology and Surgery, International University of Health and Welfare Mita Hospital, Tokyo, Japan; ${ }^{4}$ Department of Otolaryngology-Head and Neck Surgery, Nagoya City University Graduate School of Medical Sciences, Nagoya, Japan; ${ }^{5}$ Department of Otolaryngology-Head and Neck Surgery, Hokkaido University Graduate School of Medicine, Sapporo, Japan; ${ }^{6}$ Department of Otolaryngology, Tokyo Medical University School of Medicine, Tokyo, Japan; ${ }^{7}$ Department of Otolaryngology-Head and Neck Surgery, Tokai University School of Medicine, Isehara, Japan; ${ }^{8}$ Department of Head and Neck Surgery, Niigata Cancer Center Hospital, Niigata, Japan; ${ }^{9}$ Department of Pathology, Cancer Institute Hospital, Japanese Foundation for Cancer Research, Tokyo, Japan; ${ }^{10}$ Department of Otolaryngology, Head and Neck Surgery, Chiba University Graduate School of Medicine, Chiba, Japan; ${ }^{11}$ Department of Anatomic Pathology, Tokyo Medical University School of Medicine, Tokyo, Japan
\end{abstract}

\begin{abstract}
Background. Among salivary gland malignancies, the prognosis of salivary duct carcinoma (SDC) is assumed to be the poorest. However, because of its low incidence, reliable survival estimates and prognostic factors based on a large number of patients remain to be elucidated, thereby making it impossible to standardize the optimal treatment for SDC.

Methods. We performed this multi-institutional, retrospective analysis by collecting the clinical information of 141 patients with SDC without distant metastasis who underwent curative surgery as the initial treatment to elucidate overall survival (OS) and disease-free survival (DFS) along with their prognostic factors.

Results. The 3-year OS and DFS rates were 70.5 and $38.2 \%$, respectively. Multivariate analysis revealed that age $\geq 65$ years $(p<0.001)$ and $\mathrm{N} 1$ and $\mathrm{N} 2(p=0.047$ and $<0.001$, respectively) were independent prognostic factors
\end{abstract}

(C) The Author(s) 2016. This article is published with open access at Springerlink.com

First Received: 2 October 2015;

Published Online: 20 January 2016

Y. Imanishi, MD

e-mail: yorihisa@ja2.so-net.ne.jp; yorihisa@a6.keio.jp for OS, whereas the primary site of the minor salivary and sublingual gland $(p<0.001)$ and $\mathrm{N} 2(p<0.001)$ were those for DFS. The most common treatment failure was distant metastasis (55 patients, $39.0 \%$ ). For early parotid SDC, neither total parotidectomy in the patients with early $\mathrm{T}$ stage nor nerve resection in the patients without facial nerve palsy showed survival benefits.

Conclusions. Advanced N stage independently affects both OS and DFS. Partial parotidectomy with facial nerve preservation could be a less invasive standard surgical procedure for parotid gland SDC in the early $\mathrm{T}$ stage without facial nerve palsy. Effective systemic therapy is imperative to improve DFS of SDC.

Salivary duct carcinoma (SDC), an aggressive and relatively rare tumor arising from the ductal epithelium of the salivary gland, represents approximately $10 \%$ of all salivary gland malignancies. ${ }^{1,2}$ Although SDC was first reported by Kleinsasser in 1968, it was officially defined as a distinctive clinicopathologic entity in the revised histologic classification of salivary gland neoplasms by the World Health Organization in $1990{ }^{3,4}$ SDC morphologically resembles ductal carcinoma of the breast while considering the histological features, such as ductal 
formation with a solid, cystic, cribriform, or papillary structure; elements of intraductal comedonecrosis; calcification; and a reactive desmoplastic stroma. ${ }^{1,2,5,6}$ In general, SDC tends to be diagnosed in men in their $60 \mathrm{~s}$ or $70 \mathrm{~s}$ predominantly in the parotid gland, which is the most common primary site. ${ }^{1,2,7,8}$ Clinically, SDC is characterized by aggressive behavior with a tendency for rapid progression, including early facial nerve involvement, extra-glandular invasion, and high incidence of regional and distant metastasis, leading to tumor-related death. ${ }^{7-10}$

Similar to other high-grade salivary gland tumors, the standard treatment for resectable tumors is radical surgery, including ipsilateral neck dissection, followed by postoperative adjuvant radiotherapy. Unfortunately, because of the high incidence of locoregional recurrence and distant metastases, the latter reportedly being 40-70\%, most patients die of the disease within 3 years. Hence, the prognosis of SDC appears to be one of the poorest among salivary gland cancers. ${ }^{6,8-13}$ However, due to its very low incidence, these previous studies on clinical outcomes with survival analysis have been performed in a small number of patients, ranging from 13 to 56. Thus, reliable survival estimates and prognostic factors of SDC based on a large number of patients remain to be clarified, except for a recent study that analyzed the data from the Surveillance, Epidemiology and End Results (SEER) program of the National Cancer Institute. ${ }^{14}$ For the same reason, it remains impossible to conduct large-scale clinical trials to discover a promising chemotherapy protocol for patients with SDC or other salivary gland malignancies.

To overcome the inevitable limitations of single-institute clinical investigations, we organized a multiinstitutional research group to collect the clinical and histopathological information from a large number of patients with SDC. We performed this retrospective analysis to elucidate the clinical prognostic factors along with the clinical outcomes of the patients with SDC treated with curative intent at seven tertiary hospitals.

\section{METHODS}

\section{Patients and Treatments}

The present study was approved by the Institutional Ethics Review Board of each of the seven institutions that participated in the study; the requirement for obtaining informed consent was waived owing to the retrospective nature of the analysis. The clinical data of 186 patients with SDC diagnosed at those institutions between 1992 and 2014 were obtained, of which 141 patients without distant metastasis at initial diagnosis who underwent curative surgery as the initial treatment were enrolled in this study.
All patients underwent central pathological review by two expert pathologists (T.N. and Y.S.) and were staged according to the UICC TNM classification and staging system (2010, 7 th edition). ${ }^{15}$

The surgical procedure for the primary tumor was determined according to the tumor site and its extent, which were precisely evaluated by imaging diagnosis using CT, MRI, US, and/or PET-CT. Neck dissection was performed for patients with lymph node metastasis (N1 and N2 patients) and/or those (including N0 patients) with histopathological diagnosis of high-grade malignancy indicated preoperatively by aspiration cytology. Postoperative radiotherapy of 60-66 Gy was given when any of the resection margins was positive or equivocal and/or lymph node metastasis was pathologically positive. In cases of grossly positive margins and/or extracapsular spread, concurrent chemoradiotherapy or adjuvant chemotherapy was administered at the surgeon's discretion.

\section{Statistical Analysis}

Overall survival (OS) and disease-free survival (DFS) rates were estimated using the Kaplan-Meier method. The prognostic effects of patient/disease factors, including age, sex, primary site, tumor size, facial nerve palsy, $\mathrm{N}$ classification, rapid tumor progression (defined as a rapid growth of the primary tumor as observed by the patient immediately prior to visiting a clinic or hospital), and pain (defined as a pain that the patient had in the lesion), were first examined by univariate analysis using the log-rank test and the Cox's proportional hazards model; the latter further assessed the independent significance of these factors on multivariate analysis without sequential and/or stepwise variable selection. $p$ values $<0.05$ were considered statistically significant. All statistical analyses were performed using STATA ver. 13 (StataCorp., TX).

We also investigated the patterns of treatment failure, including locoregional recurrence and distant metastasis. To evaluate the possible validity of less invasive procedures for SDC of the parotid gland in the early T stage and/ or without facial nerve palsy, we examined differences in the clinical outcomes including locoregional control (LRC) rate between patients who underwent partial parotidectomy and total parotidectomy, as well as those between nerve preservation and nerve resection.

\section{RESULTS}

\section{Patient Characteristics}

The clinical and demographic characteristics of the 141 patients that comprised 119 men $(84.4 \%)$ and 22 women 
TABLE 1 Patient characteristics $(n=141)$

\begin{tabular}{|c|c|c|}
\hline & $N$ & $(\%)$ \\
\hline \multicolumn{3}{|l|}{ Age } \\
\hline$<65$ & 78 & $(55.3)$ \\
\hline$\geq 65$ & 63 & $(44.7)$ \\
\hline \multicolumn{3}{|l|}{ Sex } \\
\hline Men & 119 & $(84.4)$ \\
\hline Women & 22 & $(15.6)$ \\
\hline \multicolumn{3}{|l|}{ Primary tumor site } \\
\hline Parotid gland & 112 & $(79.4)$ \\
\hline Submandibular gland & 25 & $(17.7)$ \\
\hline Minor salivary gland & 3 & $(2.1)$ \\
\hline Sublingual gland & 1 & $(0.7)$ \\
\hline \multicolumn{3}{|l|}{ Tumor size } \\
\hline$<40 \mathrm{~mm}$ & 85 & $(60.3)$ \\
\hline$\geq 40 \mathrm{~mm}$ & 53 & $(37.6)$ \\
\hline Unknown & 3 & $(2.1)$ \\
\hline \multicolumn{3}{|l|}{ Facial nerve palsy } \\
\hline- & 96 & $(68.1)$ \\
\hline+ & 43 & $(30.5)$ \\
\hline Unknown & 2 & $(1.4)$ \\
\hline \multicolumn{3}{|l|}{$\mathrm{N}$ classification } \\
\hline 0 & 70 & $(49.6)$ \\
\hline 1 & 9 & $(6.4)$ \\
\hline 2 & 62 & $(44.0)$ \\
\hline \multicolumn{3}{|l|}{ Rapid progression } \\
\hline- & 101 & $(71.6)$ \\
\hline+ & 34 & $(24.1)$ \\
\hline Unknown & 6 & $(4.3)$ \\
\hline \multicolumn{3}{|l|}{ Pain } \\
\hline- & 112 & $(79.4)$ \\
\hline+ & 25 & $(17.7)$ \\
\hline Unknown & 4 & $(2.8)$ \\
\hline \multicolumn{3}{|l|}{ PORT } \\
\hline- & 58 & $(41.1)$ \\
\hline $\mathrm{RT}$ & 58 & $(41.1)$ \\
\hline CRT & 25 & $(17.7)$ \\
\hline
\end{tabular}

PORT post-operative radiotherapy, $R T$ radiotherapy, $C R T$ chemoradiation

$(15.6 \%)$ are summarized in Table 1 . The median age at initial diagnosis was 64 (range 26-85) years. The primary tumor site was the parotid gland in 112 patients (79.4\%), submandibular gland in $25(17.7 \%)$, minor salivary gland in $3(2.1 \%)$, and sublingual gland in $1(0.7 \%)$. Approximately two-thirds of the patients (93 patients, 66.0\%) presented with a T3/T4 tumor. Lymph node metastasis was clinically positive $(\mathrm{N} 1 / \mathrm{N} 2)$ in more than a half of the patients (71 patients, $50.4 \%$ ). Among the 138 patients with primary tumor size information, 85 patients had tumors $<40 \mathrm{~mm}$ in size and 53 patients had tumors $\geq 40 \mathrm{~mm}$. Forty-three patients $(30.5 \%)$ presented with facial nerve palsy, all of whom had primary tumors at the parotid gland. Thirty-four patients $(24.1 \%)$ had a recent history of rapid progression of the tumor, and 25 patients $(17.7 \%)$ experienced pain due to the tumor.

While 83 patients underwent surgery followed by adjuvant radiotherapy or chemoradiotherapy, 51 patients underwent surgery alone, and the remaining 7 patients received adjuvant chemotherapy without radiotherapy. Surgical procedures were extended total parotidectomy (composite resection of the parotid gland along with surrounding structures) in 31 patients, total parotidectomy in 60, partial parotidectomy (lobectomy) in 19, parapharyngeal tumorectomy in 4 , submandibular gland resection in 25 , and partial maxillectomy and extended sublingual gland resection in 1 each.

\section{Clinical Outcome and Survival Analysis}

The median follow-up period was 36 months. At the time of analysis, 55 patients were alive without the disease (including 7 patients who underwent secondary or tertiary salvage treatment and remained recurrence-free), 44 died of disease recurrences ( 2 of local, 1 of local and distant, 2 of regional, 7 of regional and distant, 25 of distant, 1 of treatment-related, and 6 unspecified), 29 patients were alive with the disease, and 13 died of other causes. The 3year OS and DFS rates were $70.5 \%$ [95\% confidence interval (CI) 61.4-77.8\%] and 38.2\% (95\% CI 29.5$46.9 \%$ ), respectively (Fig. 1a, b).

The results of the univariate analysis for the prognostic factors determined by log-rank tests are displayed, in part, in Fig. 1c-f, whereas those analyzed by Cox's hazards model are summarized in Table 2. The OS was significantly worse in patients aged $\geq 65$ years $(p=0.002$, vs. $<65$ years), those with $\mathrm{N} 1$ and $\mathrm{N} 2$ ( $p=0.036$ and $<0.001$, respectively, vs. N0), and those showing rapid progression $(p=0.003)$, whereas no significant difference was found regarding other factors. The DFS was significantly worse when primary tumors were at the minor salivary gland and sublingual gland ( $p=0.009$, vs. the parotid gland), in patients with $\mathrm{N} 2(p<0.001$, vs. N0), those showing rapid progression $(p=0.014)$, and those with pain $(p=0.032)$, whereas other factors showed no significant difference. Multivariate analysis revealed that age $\geq 65$ years [hazard ratio $(\mathrm{HR})=2.96, p<0.001$, vs. $<65$ years $]$ and $\mathrm{N} 1$ and $\mathrm{N} 2(\mathrm{HR}=2.97$ and 4.01, $p=0.047$ and $<0.001$, respectively, vs. N0) were independent prognostic factors for OS, 
$\mathbf{a}$

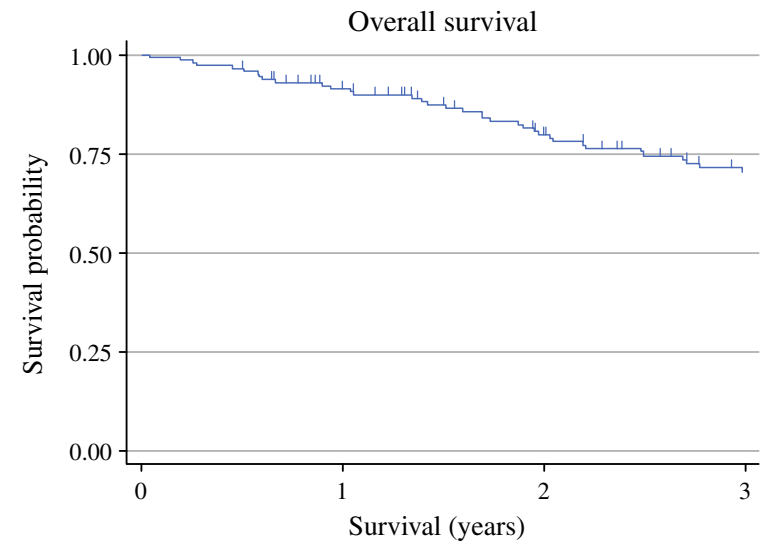

Number at risk

141

119

93

71

c

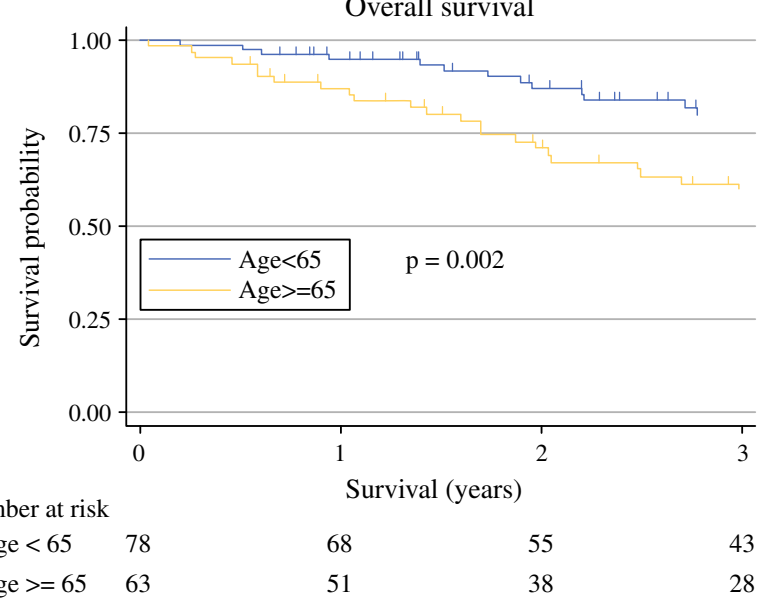

e

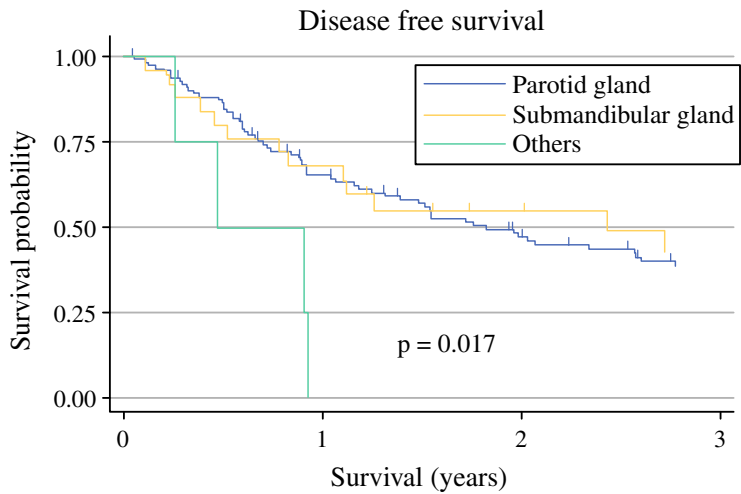

Number at risk

Parotid 112

Submand 25

Others 4

FIG. 1 Actuarial survival curves of patients with SDC. a Overall survival (OS) and b disease-free survival (DFS) of all 141 patients with SDC. The 3-year OS and DFS rates were 70.5 and $38.2 \%$, respectively. The survival curves according to each of the prognostic factors that were found to be significant on both univariate analysis b

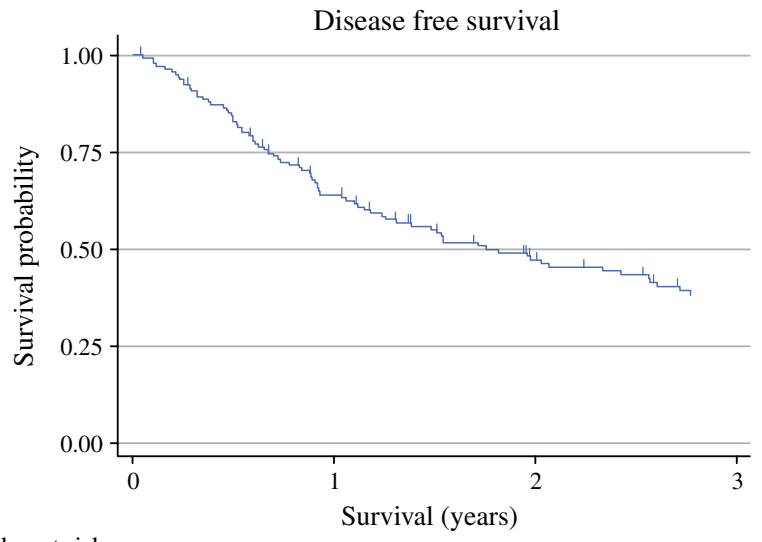

Number at risk

141

81

51

37

d

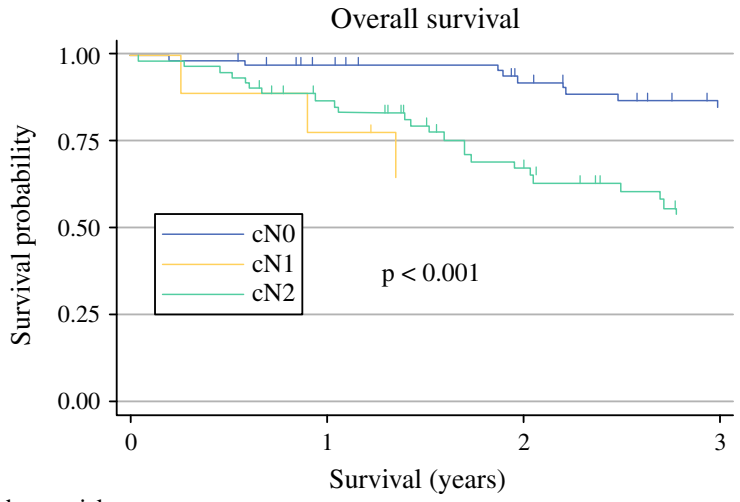

Number at risk

$\begin{array}{ccccc}\mathrm{cN} 0 & 70 & 62 & 55 & 45 \\ \mathrm{cN} 1 & 9 & 7 & 5 & 5 \\ \mathrm{cN} 2 & 62 & 50 & 33 & 21\end{array}$

f

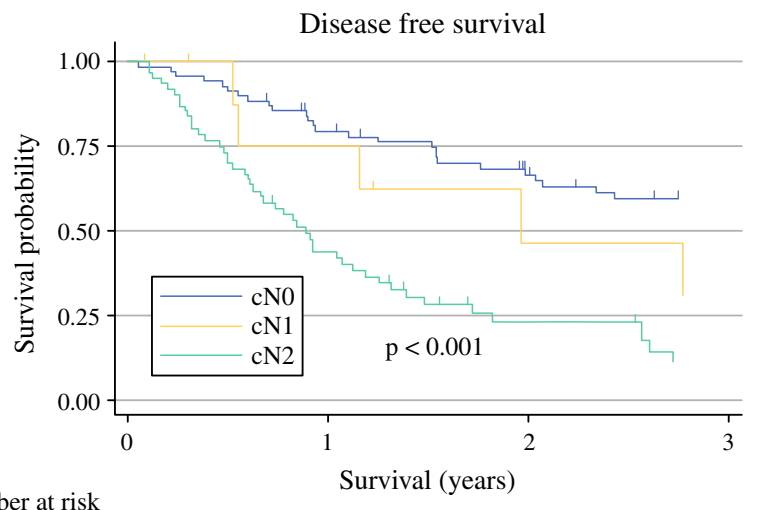

Number at risk

$\begin{array}{ccccc}\mathrm{cN} 0 & 70 & 51 & 39 & 31 \\ \mathrm{cN} 1 & 9 & 6 & 3 & 2 \\ \mathrm{cN} 2 & 62 & 24 & 9 & 4\end{array}$

with the log-rank test and multivariate analysis with Cox's hazards model are shown as follows: c, $\mathbf{d}$ OS according to age $(p=0.002)$ and $\mathrm{N}$ classification (shown as $\mathrm{cN}, p<0.001$ ), respectively. e, f DFS according to primary tumor site $(p=0.017)$ and $\mathrm{N}$ classification (shown as $\mathrm{cN}, p<0.001$ ), respectively 
TABLE 2 Univariate and multivariate analysis for overall survival and disease-free survival $(n=141)$

\begin{tabular}{|c|c|c|c|c|c|c|c|c|c|c|c|c|c|}
\hline \multirow[t]{3}{*}{ Variables } & \multirow[t]{3}{*}{$N$} & \multicolumn{6}{|c|}{ Overall survival } & \multicolumn{6}{|c|}{ Disease-free survival } \\
\hline & & \multicolumn{3}{|c|}{ Univariate analysis } & \multicolumn{3}{|c|}{ Multivariate analysis } & \multicolumn{3}{|c|}{ Univariate analysis } & \multicolumn{3}{|c|}{ Multivariate analysis } \\
\hline & & HR & $95 \% \mathrm{CI}$ & $p$ value & HR & $95 \% \mathrm{CI}$ & $p$ value & HR & $95 \% \mathrm{CI}$ & $p$ value & HR & $95 \% \mathrm{CI}$ & $p$ value \\
\hline \multicolumn{14}{|l|}{ Age } \\
\hline$<65$ & 78 & 1.00 & - & - & 1.00 & - & - & 1.00 & - & - & 1.00 & - & - \\
\hline$\geq 65$ & 63 & 2.33 & $1.36-3.99$ & $0.002 *$ & 2.96 & $1.62-5.41$ & $<0.001 *$ & 1.20 & $0.78-1.86$ & 0.405 & 1.62 & $0.98-2.68$ & 0.058 \\
\hline \multicolumn{14}{|l|}{ Sex } \\
\hline Men & 119 & 1.00 & - & - & 1.00 & - & - & 1.00 & - & - & 1.00 & - & - \\
\hline Women & 22 & 0.96 & $0.47-1.97$ & 0.916 & 1.38 & $0.60-3.19$ & 0.448 & 0.69 & $0.36-1.34$ & 0.276 & 0.71 & $0.34-1.49$ & 0.370 \\
\hline \multicolumn{14}{|l|}{ Primary tumor site } \\
\hline Parotid gland & 112 & 1.00 & - & - & 1.00 & - & - & 1.00 & - & - & 1.00 & - & - \\
\hline Submandibular gland & 25 & 1.17 & $0.60-2.27$ & 0.648 & 1.37 & $0.59-3.16$ & 0.459 & 1.03 & $0.59-1.82$ & 0.906 & 1.48 & $0.72-3.05$ & 0.284 \\
\hline Others & 4 & 1.54 & $0.37-6.39$ & 0.551 & 1.54 & $0.29-8.17$ & 0.613 & 3.98 & $1.42-11.15$ & $0.009 *$ & 8.46 & $2.61-27.45$ & $<0.001 *$ \\
\hline \multicolumn{14}{|l|}{ Tumor size } \\
\hline$<40 \mathrm{~mm}$ & 85 & 1.00 & - & - & 1.00 & - & - & 1.00 & - & - & 1.00 & - & - \\
\hline$\geq 40 \mathrm{~mm}$ & 53 & 1.32 & $0.76-2.33$ & 0.324 & 1.03 & $0.54-1.96$ & 0.931 & 1.36 & $0.86-2.13$ & 0.185 & 1.29 & $0.77-2.16$ & 0.339 \\
\hline Unknown & 3 & - & - & - & - & - & - & - & - & - & - & - & - \\
\hline \multicolumn{14}{|l|}{ Facial nerve palsy } \\
\hline- & 96 & 1.00 & - & - & 1.00 & - & - & 1.00 & - & - & 1.00 & - & - \\
\hline+ & 43 & 1.39 & $0.80-2.40$ & 0.239 & 1.50 & $0.77-2.94$ & 0.233 & 1.49 & $0.95-2.35$ & 0.085 & 1.69 & $0.99-2.88$ & 0.054 \\
\hline Unknown & 2 & - & - & - & - & - & - & - & - & - & - & - & - \\
\hline \multicolumn{14}{|l|}{$\mathrm{N}$ classification } \\
\hline 0 & 70 & 1.00 & - & - & 1.00 & - & - & 1.00 & - & - & 1.00 & - & - \\
\hline 1 & 9 & 2.70 & $1.07-6.80$ & $0.036^{*}$ & 2.97 & $1.02-8.70$ & $0.047 *$ & 2.12 & $0.91-5.36$ & 0.078 & 1.92 & $0.71-5.18$ & 0.195 \\
\hline 2 & 62 & 3.29 & $1.83-5.91$ & $<0.001 *$ & 4.01 & $2.04-7.90$ & $<0.001 *$ & 4.05 & $2.51-6.55$ & $<0.001 *$ & 3.94 & $2.34-6.63$ & $<0.001^{*}$ \\
\hline \multicolumn{14}{|l|}{ Rapid progression } \\
\hline- & 101 & 1.00 & - & - & 1.00 & - & - & 1.00 & - & - & 1.00 & - & - \\
\hline+ & 34 & 2.40 & $1.36-4.24$ & $0.003 *$ & 1.73 & $0.87-3.42$ & 0.116 & 1.82 & $1.13-2.93$ & $0.014 *$ & 1.18 & $0.68-2.07$ & 0.556 \\
\hline Unknown & 6 & - & - & - & - & - & - & - & - & - & - & - & - \\
\hline \multicolumn{14}{|l|}{ Pain } \\
\hline- & 112 & 1.00 & - & - & 1.00 & - & - & 1.00 & - & - & 1.00 & - & - \\
\hline+ & 25 & 1.51 & $0.82-2.78$ & 0.182 & 1.34 & $0.63-2.84$ & 0.451 & 1.74 & $1.05-2.89$ & $0.032 *$ & 1.78 & $0.94-3.35$ & 0.076 \\
\hline Unknown & 4 & - & - & - & - & - & - & - & - & - & - & - & - \\
\hline
\end{tabular}

$H R$ hazard ratio, $C I$ confidence interval

* Statistically significant $(p<0.05)$

while the primary sites of the minor salivary gland and sublingual gland ( $\mathrm{HR}=8.46, p<0.001$, vs. the parotid gland $)$ and $\mathrm{N} 2(\mathrm{HR}=3.94, p<0.001$, vs. N0) were independent prognostic factors for DFS (Table 2).

\section{Patterns of Treatment Failure}

As shown in Fig. 2, treatment failure occurred in 78 patients $(55.3 \%)$, including $13(9.2 \%)$ local, 18 (12.8\%) regional, and $55(39.0 \%)$ distant failures, of which 48 were without locoregional failure. The most common sites of distant metastasis were the lungs $(n=32)$, followed by the bones $(n=11)$, liver $(n=5)$, and brain $(n=3)$.

\section{Partial Parotidectomy vs. Total Parotidectomy for Parotid SDC in the Early T Stage}

The clinical outcomes of 33 patients with SDC of T1-2 of the parotid gland who underwent partial parotidectomy or total parotidectomy were compared (Table 3a). Univariate analysis, as well as multivariate analysis adjusted for age, sex, tumor size, $\mathrm{N}$ classification, rapid progression, pain, and adjuvant radiotherapy, showed no significant difference in OS, DFS, and LRC. 


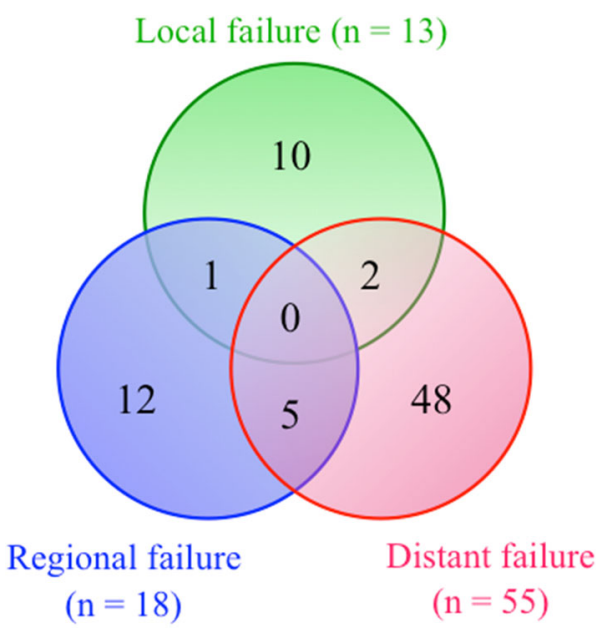

FIG. 2 Distribution of treatment failure patterns in 141 patients with SDC. Thirteen cases $(9.2 \%)$ of local, 18 cases (12.8\%) of regional, and 55 cases $(39.0 \%)$ of distant failures were observed in a total of 78 patients

\section{Nerve Preservation vs. Nerve Resection for Parotid SDC Without Facial Nerve Palsy}

The clinical outcomes of 68 patients with SDC without facial nerve palsy who underwent surgery with nerve preservation or nerve resection were compared (Table $3 b$ ). Univariate analysis showed that OS, DFS, and LRC of the patients who underwent facial nerve resection were significantly worse than those whose facial nerves were preserved. However, no significant difference was found in OS, DFS, and LRC, on multivariate analysis adjusted as described above.

\section{DISCUSSION}

There has been an absence of studies analyzing the survival and prognostic factors of SDC based on a large number of patients because of its low incidence. To the best of our knowledge, the present study analyzed the largest series of patients with SDC, except for a U.S. study using the SEER data in which only disease-specific survival (DSS) was described. ${ }^{14}$ Although the retrospective nature of the study inevitably could not exclude selection bias, especially for additional treatment after surgery, the results obtained from our study could provide reliable survival estimates and prognostic factors for patients with SDC.

Two early studies with small cohorts $(n=26$ each) in the 1990s reported considerably poor outcomes of 2-year OS of 42.3 and $58 \%$, and 5-year OS of 11.5 and $30 \%$,

TABLE 3 The impact of total parotidectomy in early T stage SDC $(n=33)$ and facial nerve resection in facial nerve palsy-negative SDC $(n=68)$ of the parotid gland on clinical outcome

(a) Early T stage SDC of the parotid gland $(n=33)$

\begin{tabular}{|c|c|c|c|c|c|c|c|c|}
\hline \multirow[t]{2}{*}{ Endpoint } & \multirow{2}{*}{$\begin{array}{l}\text { Procedure } \\
\text { Extent of parotidectomy }\end{array}$} & \multirow[t]{2}{*}{$N$} & \multicolumn{3}{|c|}{ Univariate analysis } & \multicolumn{3}{|c|}{ Multivariate analysis $^{\mathrm{a}}$} \\
\hline & & & HR & $95 \% \mathrm{CI}$ & $p$ value & HR & $95 \% \mathrm{CI}$ & $p$ value \\
\hline \multirow[t]{2}{*}{ Overall survival } & Partial & 15 & 1.00 & - & - & 1.00 & - & - \\
\hline & Total & 18 & 1.24 & $0.29-5.21$ & 0.771 & not calculable & - & - \\
\hline \multirow[t]{2}{*}{ Disease-free survival } & Partial & 15 & 1.00 & - & - & 1.00 & - & - \\
\hline & Total & 18 & 1.60 & $0.48-5.32$ & 0.443 & 0.18 & $0.01-2.83$ & 0.225 \\
\hline \multirow[t]{2}{*}{ Locoregional control } & Partial & 15 & 1.00 & - & - & 1.00 & - & - \\
\hline & Total & 18 & 2.16 & $0.22-20.90$ & 0.507 & not calculable & - & - \\
\hline
\end{tabular}

(b) Facial nerve palsy-negative SDC of the parotid gland $(n=68)$

\begin{tabular}{|c|c|c|c|c|c|c|c|c|}
\hline \multirow[t]{2}{*}{ Endpoint } & \multirow{2}{*}{$\begin{array}{l}\text { Procedure } \\
\text { Facial nerve }\end{array}$} & \multirow[t]{2}{*}{$N$} & \multicolumn{3}{|c|}{ Univariate analysis } & \multicolumn{3}{|c|}{ Multivariate analysis $^{\mathrm{a}}$} \\
\hline & & & HR & $95 \% \mathrm{CI}$ & $p$ value & HR & $95 \% \mathrm{CI}$ & $p$ value \\
\hline \multirow[t]{2}{*}{ Overall survival } & Preservation & 27 & 1.00 & - & - & 1.00 & - & - \\
\hline & Resection & 41 & 2.92 & $1.08-7.90$ & $0.035^{*}$ & 0.91 & $0.23-3.53$ & 0.890 \\
\hline \multirow[t]{2}{*}{ Disease-free survival } & Preservation & 27 & 1.00 & - & - & 1.00 & - & - \\
\hline & Resection & 41 & 3.54 & $1.54-8.16$ & $0.003 *$ & 2.10 & $0.71-6.21$ & 0.179 \\
\hline \multirow[t]{2}{*}{ Locoregional control } & Preservation & 27 & 1.00 & - & - & 1.00 & - & - \\
\hline & Resection & 41 & 4.57 & $1.02-20.47$ & $0.047 *$ & 1.63 & $0.26-10.23$ & 0.604 \\
\hline
\end{tabular}

$H R$ hazard ratio, $C I$ confidence interval

* Statistically significant $(p<0.05)$

a Adjusted by age, sex, tumor size, $N$ classification, rapid progression, pain, and adjuvant radiotherapy 
respectively. ${ }^{8,10}$ Although a later study with a larger cohort $(n=59)$ also showed a comparable outcome of the 2-, 3-, and 5-year OS of $62.3,42.7$, and $26.9 \%$, respectively, more recent studies with similar cohort sizes reported somewhat better 5-year OS outcomes of $55.1 \%(n=35)$, $42 \%(n=56)$, and $43 \%(n=54)$, suggesting the benefit of intensification of both surgery and adjuvant radiotherapy regarding the treatment outcomes. ${ }^{12,13,16,17}$ However, there were noticeably large differences between OS and DFS, i.e., the 5-year DFS was $29 \% .^{12}$ In our study, the 3-year OS and DFS were 70.5 and $38.2 \%$, respectively. This reflected a considerably high ratio of treatment failure (55.3\% in our study) for this disease.

Multivariate analysis in the present study showed, for the first time, that advanced $\mathrm{N}$ stage independently affects both OS and DFS in patients with SDC. Significant correlation of the $\mathrm{N}$ classification with OS has been previously reported, although those results were based on only univariate analyses with much smaller sample sizes. ${ }^{8,10,16}$ Our findings also were partially consistent with those of the SEER study ( $n=228$ ), in which multivariate analysis showed that age and $\mathrm{N}$ classification, as well as tumor size and grade, were independent prognostic factors for OS and DSS (DFS was not analyzed). ${ }^{14}$ Although the influence of age on prognosis may depend on the cancer type, the prognostic significance revealed in the OS of patients with SDC may reflect an increased risk of death in the elderly owing to other fatal diseases generally associated with aging.

In an early study of 30 patients with SDC that included 13 patients with distant metastasis at initial diagnosis, multivariate analysis showed that tumor diameter and distant metastasis were independent prognostic factors for OS. ${ }^{18}$ Given that some subjects had distant metastasis, unlike most other studies, distant metastasis could inevitably be the most unfavorable predictor of survival unless an effective systemic therapy becomes available for such patients. In another recent study that employed multivariate analysis, lymphovascular invasion and perineural invasion were found to be independent histopathological prognostic factors for OS, suggesting a possible benefit of evaluating histopathological characteristics for predicting survival of patients with SDC. ${ }^{17}$

In our cohort, the most common form of treatment failure was distant metastasis, which corroborates the findings of a limited number of previous observations in smaller cohorts. ${ }^{13,17}$ Consistent with our findings, the lungs and bones were the most common sites of distant metastasis in SDC. ${ }^{11,13,17}$ Such a high ratio of distant metastasis is presumed to be the leading cause of low DFS. Although extended resection with wider margins combined with intensified adjuvant radiotherapy have seemingly contributed to better treatment outcomes of SDC by improving LRC, these strategies alone cannot prevent the development of delayed distant metastasis. Therefore, an effective systemic therapy after curative surgery is imperative to improve DFS of SDC patients. Unfortunately, there has been no evidence-based chemotherapy regimen for salivary gland cancers including SDC. ${ }^{19}$ Recent immunohistochemical studies reported that androgen receptor (AR) expression is observed in 43-92\% of SDC, whereas HER2 expression is observed in 26-77\%, both of which were confirmed in our separated subanalysis (data not shown), suggesting a potential role for agents acting on these receptors as possible molecular-targeted therapy for SDC. ${ }^{16,20-31}$ Currently, our multi-institutional joint research group is conducting interventional clinical studies of systemic therapy targeting $\mathrm{AR}$ and HER2 in combination with chemotherapy for recurrent/metastatic SDC.

Although preservation of the facial nerve has been recommended during parotid gland cancer surgery if nerve function was preoperatively normal, its applicability for SDC remains to be determined. ${ }^{32,33}$ In our subanalyses regarding patients with early SDC of the parotid gland, neither total parotidectomy in patients with early $\mathrm{T}$ stage nor nerve resection in patients without facial nerve palsy showed a survival benefit compared with those treated with partial parotidectomy and nerve preservation, respectively. Although these results should be interpreted while considering the possible selection bias because of the retrospective nature of the study, our results suggest that even in SDC of the parotid gland, partial parotidectomy with facial nerve preservation could be the standard procedure for primary tumors in early $\mathrm{T}$ stage without facial nerve palsy.

\section{CONCLUSIONS}

Our multi-institutional joint study revealed that advanced $\mathrm{N}$ stage independently affects both OS and DFS. Given the high incidence of distant failure, an effective systemic therapy is essential for improving DFS of SDC. Partial parotidectomy with facial nerve preservation may constitute a less invasive standard surgical procedure for parotid gland SDC in the early $\mathrm{T}$ stage without facial nerve palsy.

ACKNOWLEDGMENT This study was supported in part by JSPS Grants-in-Aid for Scientific Research (C) to Y. Tada (No. 15K10823) and Y. Imanishi (No. 25462692). The authors thank Editage (www. editage.jp) for English language editing.

\section{DISCLOSURE None.}

OPEN ACCESS This article is distributed under the terms of the Creative Commons Attribution 4.0 International License (http:// creativecommons.org/licenses/by/4.0/), which permits unrestricted use, distribution, and reproduction in any medium, provided you give appropriate credit to the original author(s) and the source, provide a link to the Creative Commons license, and indicate if changes were made. 


\section{REFERENCES}

1. Barnes L, Eveson JW, Reichart P, Sidaransky D, eds. World Health Organization classification of tumours. Pathology and genetics of head and neck tumours. Lyon: IARC Press; 2005.

2. McHugh JB, Visscher DW, Barnes EL. Update on selected salivary gland neoplasms. Arch Pathol Lab Med. 2009;133:176374.

3. Kleinsasser O, Klein HJ, Hubner G. Salivary duct carcinoma. A group of salivary gland tumors analogous to mammary duct carcinoma. Arch Klin Exp Ohren Nasen Kehlkopfheilkd. 1968;192:100-5.

4. Seifert G, Brocheriou C, Cardesa A, Eveson JW. WHO International histological classification of tumours. Tentative histological classification of salivary gland tumours. Pathol Res Pract. 1990;186:555-81.

5. Etges A, Pinto DS, Jr., Kowalski LP, Soares FA, Araujo VC. Salivary duct carcinoma: immunohistochemical profile of an aggressive salivary gland tumour. J Clin Pathol. 2003;56:914-8.

6. Hosal AS, Fan C, Barnes L, Myers EN. Salivary duct carcinoma. Otolaryngol Head Neck Surg. 2003;129:720-5.

7. Barnes L, Rao U, Krause J, Contis L, Schwartz A, Scalamogna P. Salivary duct carcinoma. Part I. A clinicopathologic evaluation and DNA image analysis of 13 cases with review of the literature. Oral Surg Oral Med Oral Pathol. 1994;78:64-73.

8. Guzzo M, Di Palma S, Grandi C, Molinari R. Salivary duct carcinoma: clinical characteristics and treatment strategies. Head Neck. 1997;19:126-33.

9. Delgado R, Vuitch F, Albores-Saavedra J. Salivary duct carcinoma. Cancer. 1993;72:1503-12.

10. Lewis JE, McKinney BC, Weiland LH, Ferreiro JA, Olsen KD. Salivary duct carcinoma. Clinicopathologic and immunohistochemical review of 26 cases. Cancer. 1996;77:223-30.

11. Jaehne M, Roeser K, Jaekel T, Schepers JD, Albert N, Loning T. Clinical and immunohistologic typing of salivary duct carcinoma: a report of 50 cases. Cancer. 2005;103:2526-33.

12. Roh JL, Lee JI, Choi SH, et al. Prognostic factors and oncologic outcomes of 56 salivary duct carcinoma patients in a single institution: high rate of systemic failure warrants targeted therapy. Oral Oncol. 2014;50:e64-6.

13. Johnston ML, Huang SH, Waldron JN, et al. Salivary duct carcinoma: Treatment, outcomes, and patterns of failure. Head Neck. 2015. doi:10.1002/hed.24107.

14. Jayaprakash V, Merzianu M, Warren GW, et al. Survival rates and prognostic factors for infiltrating salivary duct carcinoma: analysis of 228 cases from the Surveillance, Epidemiology, and End Results database. Head Neck. 2014;36:694-701.

15. AJCC cancer staging manual. 7th ed. New York: Springer; 2010.

16. Williams MD, Roberts D, Blumenschein GR Jr., et al. Differential expression of hormonal and growth factor receptors in salivary duct carcinomas: biologic significance and potential role in therapeutic stratification of patients. Am J Surg Pathol. 2007;31:1645-52.

17. Kim JY, Lee S, Cho KJ, et al. Treatment results of post-operative radiotherapy in patients with salivary duct carcinoma of the major salivary glands. Br J Radiol. 2012;85:e947-52.

18. Felix A, El-Naggar AK, Press MF, et al. Prognostic significance of biomarkers (c-erbB-2, p53, proliferating cell nuclear antigen, and DNA content) in salivary duct carcinoma. Hum Pathol. 1996;27:561-6.

19. Surakanti SG, Agulnik M. Salivary gland malignancies: the role for chemotherapy and molecular targeted agents. Semin Oncol. 2008;35:309-19.

20. Kapadia SB, Barnes L. Expression of androgen receptor, gross cystic disease fluid protein, and CD44 in salivary duct carcinoma. Mod Pathol. 1998;11:1033-8.

21. Fan CY, Wang J, Barnes EL. Expression of androgen receptor and prostatic specific markers in salivary duct carcinoma: an immunohistochemical analysis of 13 cases and review of the literature. Am J Surg Pathol. 2000;24:579-86.

22. Hoang MP, Callender DL, Sola Gallego JJ, et al. Molecular and biomarker analyses of salivary duct carcinomas: comparison with mammary duct carcinoma. Int J Oncol. 2001;19:865-71.

23. Kay PA, Roche PC, Olsen KD. Salivary duct carcinoma: immunohistochemical analysis of androgen receptor, prostate markers and HER-2/neu oncoprotein in 40 cases [abstract]. Mod Pathol. 2001;14:150A.

24. Locati LD, Perrone F, Losa M, et al. Treatment relevant target immunophenotyping of 139 salivary gland carcinomas (SGCs). Oral Oncol. 2009;45:986-90.

25. Skalova A, Starek I, Vanecek T, et al. Expression of HER-2/neu gene and protein in salivary duct carcinomas of parotid gland as revealed by fluorescence in situ hybridization and immunohistochemistry. Histopathology. 2003;42:348-56.

26. Cornolti G, Ungari M, Morassi ML, et al. Amplification and overexpression of HER2/neu gene and HER2/neu protein in salivary duct carcinoma of the parotid gland. Arch Otolaryngol Head Neck Surg. 2007;133:1031-6.

27. Williams MD, Roberts DB, Kies MS, Mao L, Weber RS, ElNaggar AK. Genetic and expression analysis of HER-2 and EGFR genes in salivary duct carcinoma: empirical and therapeutic significance. Clin Cancer Res. 2010;16:2266-74.

28. Jaspers HC, Verbist BM, Schoffelen R, et al. Androgen receptorpositive salivary duct carcinoma: a disease entity with promising new treatment options. J Clin Oncol. 2011;29:e473-6.

29. Krishnamurthy J, Krishnamurty DM, Baker JJ, Zhen W, Lydiatt D, Ganti AK. Salivary duct carcinoma responding to trastuzumab-based therapy: case report and review of the literature. Head Neck. 2013;35:E372-5.

30. Limaye SA, Posner MR, Krane JF, et al. Trastuzumab for the treatment of salivary duct carcinoma. Oncologist. 2013;18:294300 .

31. Locati LD, Perrone F, Cortelazzi B, et al. Clinical activity of androgen deprivation therapy in patients with metastatic/relapsed androgen receptor-positive salivary gland cancers. Head Neck. 2014. doi:10.1002/hed.23940.

32. Guntinas-Lichius O, Klussmann JP, Schroeder U, Quante G, Jungehuelsing M, Stennert E. Primary parotid malignoma surgery in patients with normal preoperative facial nerve function: outcome and long-term postoperative facial nerve function. Laryngoscope. 2004;114:949-56.

33. Vander Poorten V, Bradley PJ, Takes RP, Rinaldo A, Woolgar JA, Ferlito A. Diagnosis and management of parotid carcinoma with a special focus on recent advances in molecular biology. Head Neck. 2012;34:429-40. 